\title{
High temperature stress and its influence on surface rumpling in NiCoCrAIY bond coat
}

DOI:

10.1016/j.actamat.2017.08.001

\section{Document Version}

Accepted author manuscript

Link to publication record in Manchester Research Explorer

\section{Citation for published version (APA):}

Yang, L., Zou, Z., Kou, Z., Chen, Y., Zhao, G., Zhao, X., Guo, F., \& Xiao, P. (2017). High temperature stress and its influence on surface rumpling in NiCoCrAIY bond coat. Acta Materialia, 139, 122-137.

https://doi.org/10.1016/j.actamat.2017.08.001

\section{Published in:}

Acta Materialia

\section{Citing this paper}

Please note that where the full-text provided on Manchester Research Explorer is the Author Accepted Manuscript or Proof version this may differ from the final Published version. If citing, it is advised that you check and use the publisher's definitive version.

\section{General rights}

Copyright and moral rights for the publications made accessible in the Research Explorer are retained by the authors and/or other copyright owners and it is a condition of accessing publications that users recognise and abide by the legal requirements associated with these rights.

\section{Takedown policy}

If you believe that this document breaches copyright please refer to the University of Manchester's Takedown Procedures [http://man.ac.uk/04Y6Bo] or contact uml.scholarlycommunications@manchester.ac.uk providing relevant details, so we can investigate your claim.

\section{OPEN ACCESS}




\section{High temperature stress and its influence on surface rumpling in NiCoCrAIY bond coat}

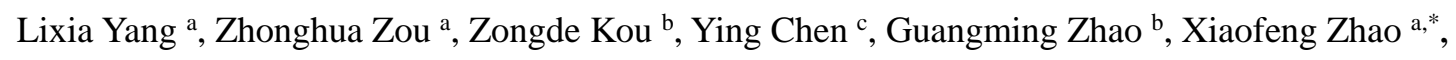

$$
\text { Fangwei Guo a }{ }^{\text {a }} \text { Ping Xiao }{ }^{\text {c,a }}
$$

a Shanghai Key Laboratory of Advanced High-temperature Materials and Precision Forming, Shanghai

$$
\text { Jiao Tong University, Shanghai, 200240, China }
$$

b State Key Laboratory of Solidification Processing, Northwestern Polytechnical University, Xi'an,

$$
\text { 710072, China }
$$

${ }^{c}$ School of Materials, University of Manchester, Grosvenor Street, Manchester M1 7HS, UK

\section{Abstract}

The objective of this work is to develop a methodology to measure the high temperature stress in the bond coat, and investigate its role on the surface rumpling. We first presented an analytical model to evaluate the high temperature stress using X-ray $\sin ^{2} \Psi$ technique coupling with the curvature measurement at room temperature. A typical NiCoCrAlY bond coat with a Hastelloy-X substrate was employed as a model sample. During exposure at $1150{ }^{\circ} \mathrm{C}$, the bond coat was under tension at high temperature, increasing parabolically from $1.05 \mathrm{MPa}$ after $12 \mathrm{~h}$ to $3.81 \mathrm{MPa}$ after $120 \mathrm{~h}$. To understand its effect on the surface rumpling, the bond coat surface roughness was recorded as a function of time, and compared with a bulk NiCoCrAlY alloy. A strong correlation between the bond coat stress and the surface roughness was identified. In addition, the origination of the bond coat stress and the rumpling mechanism were discussed.

${ }^{*}$ Corresponding author Tel./fax: +8621 54742561.

E-mail address: xiaofengzhao@sjtu.edu.cn (Xiaofeng Zhao). 
It was revealed that the high temperature stress in the bond coat was caused by the volume shrinkage from $\beta-\gamma$ transformation, mainly due to the inter-diffusion. The grain sliding accompanied with diffusional creep in response to the bond coat stress controls the roughening.

Keywords: Bond coat; Rumpling; High temperature stress; Inter-diffusion; Phase transformation. 


\section{Introduction}

Bond coat is an important part of the thermal barrier coatings (TBCs) used in industrial gas turbines. A dominant failure phenomenon has been found that the crack extends along the interface between the thermally grown oxides (TGO) and the bond coat, which is associated with the progressive surface roughening [1-3]. The roughening also termed as rumpling, ratcheting or undulation. It initiates cracks nucleation and propagation as the TBCs experience thermal cycling. Eventually, the cracks coalesce to cause the TBC to buckle or spall. Extensive works have been carried out to investigate the reasons of the rumpling. However, the mechanisms that govern the surface rumpling of the bond coat are still not fully understood. It has been generally accepted that the stress in the TGO [4-6], either from the growth at high temperature or the thermal mismatch upon cooling, is the primary driving force for the rumpling at the bond coat/TGO interface [7]. However, when thermal cycling in vacuum, the rumpling still occurs [7]. In this case, there is no (or negligible) TGO formation. This implies that the bond coat itself should be a dominant factor for rumpling. Chen and Hemker proposed that the strains caused by the martensitic transformation in the NiPtAl bond coat might be a major factor [8]. However, thermal cycling at a temperature above the martensitic temperature (i.e., 1050-1150 ${ }^{\circ} \mathrm{C}$, no martensite transformation occurs at this temperature range) the rumpling amplitude does not show significant difference with the thermal cycling at room temperature [7,9]. In addition, the bulk alloy with the same composition exhibits a much smaller propensity to rumple under the same treatment [10]. This demonstrates that the presence of substrate is essential for the surface roughening. At high temperature, interdiffusion between substrate and bond coat occurs, which could change the bond coat volume. 
Since the volume change is constrained by the substrate, a stress will be produced in the bond coat at high temperature. The high temperature stress in the bond coat might play a dominant role on the surface rumpling.

However, due to low yielding strength of the bond coat, the stress in the bond coat (e.g. $\mathrm{NiCoCrAlY)}$ at high temperature is only several MPa [11]. Determining such low stress using conventional technique (e.g., X-ray) is extremely difficult, which is beyond the detectable limit of the instruments $[10,12]$. Nevertheless, the real limitation of this approach is that it provides information on only the net elastic strain, and not the plastic deformation associated with the concurrent relaxation process. Therefore, it is necessary to develop an alternative approach to estimate the high temperature stress in the bond coat, which is crucial to understand the rumpling mechanisms.

The objective of this work is to develop a method to measure the high temperature stress in the bond coat, and investigate its role on the surface rumpling. In this study, an alternative approach, based on X-ray $\sin ^{2} \Psi$ stress and the curvature measurement at the room temperature, was employed to evaluate the stress. The basic idea is to evaluate the net plastic strain (e.g. the bond coat or the substrate) at high temperature, and then the high temperature stress can be derived based on the corresponding creep mechanisms. The paper was organized as follows. First, the methodology to determine the stress was introduced and an analytical model was developed. To validate this, a typical NiCoCrAlY bond coat on superalloy system was used as model specimen. The total strain and the elastic strain were determined using curvature and X-ray techniques, respectively. The surface roughness of the bond coat was recorded as a function of 
time and compared with that of a bulk alloy with the same composition. To elucidate the role of the bond coat stress, the progressive surface rumpling was correlated with the stress in the bond coat at high temperature. Finally, the origin of the bond coat stress as well as the mechanisms for the rumpling were also discussed.

\section{Methodology}

In this section, we first presented the methodology to quantitatively evaluate the high temperature stress in the bond coat. It is known that the bond coat system consisted of elastic and non-elastic strain after cooling from high temperature exposure. The elastic strain can be determined from X-ray and the total strain can be measured from the dimension change (e.g., curvature measurement). The non-elastic strain at the room temperature can thus be obtained and equals to the non-elastic strain at high temperature if a fast-cooling is used. Provided that the non-elastic strain at high temperature is known, the stress can be evaluated based on the creep properties of the system.

Fig. 1a is a schematic of an as-deposited bond coat/substrate system, which is slightly curved due to the quenching stress and thermal misfit stress after deposition [13,14]. $y=0$ defines as the interface between the bond coat and the substrate. $h_{\mathrm{bc}}$ and $h_{\mathrm{s}}$ are the thicknesses of bond coat and substrate, respectively. $y=h_{\mathrm{bc}}$ means the surface of the bond coat, and $y=-h_{\mathrm{s}}$ means that of the substrate. Fig. 1b shows a state during heating. Compared with the as-deposited state, the curved shape becomes flatter.

At high temperature, the TGO growth and inter-diffusion will introduce phase transformation in the bond coat, leading to shrinkage or expansion of the bond coat [15]. Assuming no 
constraint from the substrate, a strain, $\Delta \varepsilon^{T}$, will be generated in bond coat (Fig. 1c), which is a hypothetical state (framed by a dotted box). The symbol with a superscript "T" refers to the high temperature state.

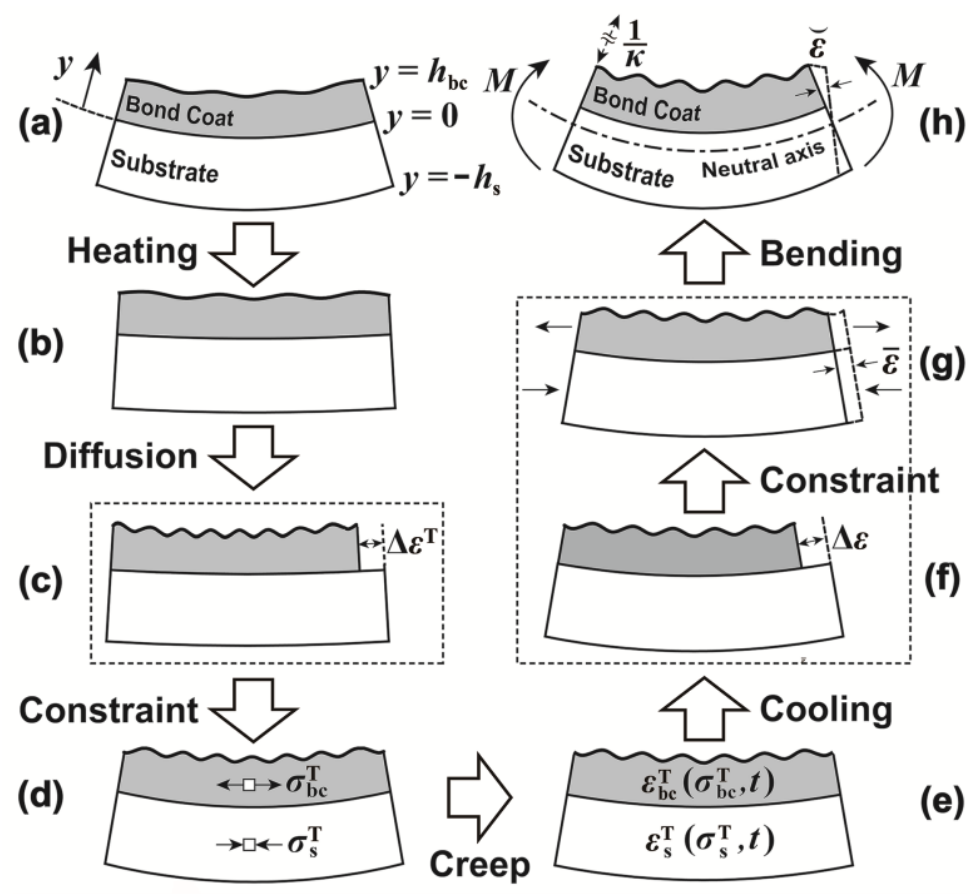

Fig. 1 Schematic illustration of the different stages of a bond coat/substrate system after heat exposure: (a) as-deposited condition; (b) a state of the system during the heating process; (c) a hypothetical state (framed by a dotted box) in which the bond coat volume changes freely and has a high temperature strain $\Delta \varepsilon^{\mathrm{T}}$, where the volume change is induced by the diffusion; (d) the constrained state of bond coat, producing a pair of stresses: $\sigma_{s}^{\mathrm{T}}, \sigma_{\mathrm{bc}}^{\mathrm{T}}$; (e) a state in which creep occurs in bond coat and substrate, producing creep strains in them: $\varepsilon_{s}^{\mathrm{T}}\left(\sigma_{s}^{\mathrm{T}}, t\right)$ and $\varepsilon_{\mathrm{bc}}^{\mathrm{T}}\left(\sigma_{\mathrm{be}}^{\mathrm{T}}, t\right)$; (f) a hypothetical state in which the bond coat is free to deform and the difference of the elastic strains in bond coat and substrate is designated as $\Delta \varepsilon$, after cooling from high temperature; $(\mathrm{g})$ a hypothetical state in which the bond coat is constrained by the substrate, the system will have a uniform elastic strain $\bar{\varepsilon}$ (since the displacement compatibility is required) and a pair of equilibrium forces (marked by arrows); (h) the final state of the bond coat/substrate system after cooling. The total strain in the substrate consists of the plastic strain and elastic strain. The elastic strain consists of a uniform component $\bar{\varepsilon}$ and a bending component $\breve{\varepsilon}$ produced by the bending moment, $M$, which is generated to balance the moment of the pair of equilibrium forces.

Due to the substrate constraint, both of the bond coat and the substrate will have internal stresses. As shown in Fig. 1d, a tensile stress $\sigma_{\mathrm{bc}}^{\mathrm{T}}$ will act on the bond coat, and a compressive stress $\sigma_{\mathrm{s}}^{\mathrm{T}}$ on the substrate. These two opposing stresses are in equilibrium, namely:

$$
\sigma_{\mathrm{bc}}^{\mathrm{T}} h_{\mathrm{bc}}=-\sigma_{\mathrm{s}}^{\mathrm{T}} h_{\mathrm{s}}
$$


where $\sigma$ is stress. The subscript "bc" represents the bond coat, and "s" substrate. Those stresses could lead to the creep deformation in both bond coat and substrate [16-18].

Mechanistically, creep deformation can be achieved by dislocation (i.e., Norton's law), grainboundary diffusion (i.e., Coble creep), lattice diffusion (i.e., Nabarro-Herring creep), etc [17], which can be written as:

$$
\varepsilon^{\mathrm{T}}=\varepsilon^{\mathrm{T}}\left(\sigma^{\mathrm{T}}, t\right)
$$

where $\varepsilon^{\mathrm{T}}$ is the creep strain, $\sigma^{\mathrm{T}}$ the creep stress, and $t$ the time. Likely, the creep strains of the bond coat and the substrate at high temperatures can be expressed as $\varepsilon_{\mathrm{bc}}^{\mathrm{T}}\left(\sigma_{\mathrm{bc}}^{\mathrm{T}}, t\right)$ and $\varepsilon_{\mathrm{s}}^{\mathrm{T}}\left(\sigma_{\mathrm{s}}^{\mathrm{T}}, t\right)$, respectively, as shown in Fig. 1e.

Once the system is cooled from high temperature, both elastic and non-elastic strains will be preserved in the system. If the bond coat is free to deform, the elastic strains in bond coat and substrate will be different and that difference is $\Delta \varepsilon$ in a hypothetical schematic (Fig. 1f). If the bond coat is constrained by the substrate (Fig. 1g), the system will have a uniform elastic strain $\bar{\varepsilon}$ (since the displacement compatibility is required) and a pair of equilibrium forces (marked by arrows). To balance the bending moment induced by this pair of forces, bending of the system occurs.

Fig. 1h depicts the final state of the system after cooling. $M$ means the bending moment. The total strain of the system at room temperature can be expressed as:

$$
\varepsilon=\varepsilon^{\mathrm{e}}+\varepsilon^{\mathrm{ne}}
$$


where $\varepsilon$ is strain, and the superscripts " $\mathrm{e}$ " and "ne" denote elastic and non-elastic, respectively. The elastic strain of the system at room temperature, $\varepsilon^{\mathrm{e}}$, is composed of a uniform component, $\bar{\varepsilon}$, and a bending component, $\breve{\varepsilon}$ (Fig. 1g-h):

$$
\varepsilon^{\mathrm{e}}=\bar{\varepsilon}+\breve{\varepsilon}=\bar{\varepsilon}+(y-\delta) \kappa^{\mathrm{e}}
$$

where $\kappa^{\mathrm{e}}$ is the curvature induced by elastic strain. $y$ is the position in the coordinate system $\left(-h_{\mathrm{s}} \leq \mathrm{y} \leq h_{\mathrm{bc}}\right) . \delta$ is the neutral axis (Fig. 1h) $[19,20]$ :

$$
\delta=\frac{E_{\mathrm{bc}} h_{\mathrm{bc}}^{2}-E_{\mathrm{s}} h_{\mathrm{s}}^{2}}{2\left(E_{\mathrm{bc}} h_{\mathrm{bc}}+E_{\mathrm{s}} h_{\mathrm{s}}\right)}
$$

where $E$ is the elastic modulus.

The elastic strains in the bond coat and the substrate, $\varepsilon_{\mathrm{bc}}^{\mathrm{e}}$ and $\varepsilon_{\mathrm{s}}^{\mathrm{e}}$, are equal to:

$$
\begin{gathered}
\varepsilon_{\mathrm{bc}}^{\mathrm{e}}=\varepsilon^{\mathrm{e}}-\Delta \varepsilon\left(0 \leq y \leq h_{\mathrm{bc}}\right) \\
\varepsilon_{\mathrm{s}}^{\mathrm{e}}=\varepsilon^{\mathrm{e}}\left(-h_{\mathrm{s}} \leq y \leq 0\right)
\end{gathered}
$$

The variables $\bar{\varepsilon}$ and $\kappa^{\mathrm{e}}$ in Eq. (4) can be determined from three boundary conditions of the model shown in Fig. 1. Firstly, the sum of forces due to the uniform strain component (i.e., the force in Fig.1g) is zero:

$$
E_{\mathrm{bc}} h_{\mathrm{bc}}(\bar{\varepsilon}-\Delta \varepsilon)+E_{\mathrm{s}} h_{\mathrm{s}} \bar{\varepsilon}=0
$$

Secondly, in Fig. 1h, the sum of forces due to the bending strain component is zero: 


$$
\int_{-h_{\mathrm{s}}}^{\delta} E_{\mathrm{s}} \breve{\varepsilon} d y+\int_{\delta}^{0} E_{\mathrm{s}} \breve{\varepsilon} d y+\int_{0}^{h_{\mathrm{bc}}} E_{\mathrm{bc}} \breve{\varepsilon} d y=0
$$

Thirdly, in Fig. 1h, the sum of bending moments is zero:

$$
\int_{-h_{\mathrm{s}}}^{\delta} E_{\mathrm{s}} \varepsilon^{\mathrm{e}} y d y+\int_{\delta}^{0} E_{\mathrm{s}} \varepsilon^{\mathrm{e}} y d y+\int_{0}^{h_{\mathrm{bc}}} E_{\mathrm{bc}}\left(\varepsilon^{\mathrm{e}}-\Delta \varepsilon\right) y d y=0
$$

Based on the above three boundary conditions, we get

$$
\begin{aligned}
& \bar{\varepsilon}=\mathrm{A}_{1} \Delta \varepsilon \\
& \mathrm{A}_{1}=\frac{E_{\mathrm{bc}} h_{\mathrm{bc}}}{E_{\mathrm{bc}} h_{\mathrm{bc}}+E_{\mathrm{s}} h_{\mathrm{s}}}
\end{aligned}
$$

and

$$
\begin{aligned}
& \kappa^{\mathrm{e}}=\mathrm{A}_{2} \Delta \varepsilon \\
& \mathrm{A}_{2}=\frac{6 E_{\mathrm{s}} E_{\mathrm{bc}} h_{\mathrm{s}} h_{\mathrm{bc}}\left(h_{\mathrm{s}}+h_{\mathrm{bc}}\right)}{2 E_{\mathrm{s}} E_{\mathrm{bc}} h_{\mathrm{s}} h_{\mathrm{bc}}\left(2 h_{\mathrm{bc}}^{2}+2 h_{\mathrm{s}}^{2}+3 h_{\mathrm{s}} h_{\mathrm{bc}}\right)+E_{\mathrm{bc}}^{2} h_{\mathrm{bc}}^{4}+E_{\mathrm{s}}^{2} h_{\mathrm{s}}^{4}}
\end{aligned}
$$

The first item on the right side of Eq. (3), $\varepsilon^{\mathrm{e}}$, can be written as a function of the elastic mismatch strain $\Delta \varepsilon$ :

$$
\varepsilon^{\mathrm{e}}=\left[\mathrm{A}_{1}+(y-\delta) \mathrm{A}_{2}\right] \Delta \varepsilon\left(-h_{\mathrm{s}} \leq y \leq h_{\mathrm{bc}}\right)
$$

Similar to $\varepsilon^{\mathrm{e}}$, the second item on the right side of Eq. (3), $\varepsilon^{\text {ne }}$, which means the non-elastic strain of the system at room temperature, is also composed of two components:

$$
\varepsilon^{\mathrm{ne}}=\varepsilon^{\mathrm{ne}, \mathrm{T}}+\varepsilon^{\mathrm{ne}, \mathrm{C}}
$$

where $\varepsilon^{\mathrm{ne}, \mathrm{T}}$ is the non-elastic strain at high temperatures, and $\varepsilon^{\mathrm{ne}, \mathrm{C}}$ is the non-elastic strain occurred during the cooling process. $\varepsilon^{\text {ne }}$ can be expressed as $[19,20]$ : 


$$
\varepsilon^{\mathrm{ne}}=(y-\delta) \kappa^{\mathrm{ne}}\left(-h_{\mathrm{s}} \leq y \leq h_{\mathrm{bc}}\right)
$$

where $\kappa^{\text {ne }}$ is the system's curvature induced by non-elastic strain.

According to Eqs. (3), (4) and (14), the total strain of the system at room temperature is equal to

$$
\begin{aligned}
& \varepsilon=\varepsilon^{\mathrm{e}}+\varepsilon^{\mathrm{ne}}=\bar{\varepsilon}+(y-\delta) \kappa \\
& \kappa=\kappa^{\mathrm{e}}+\kappa^{\mathrm{ne}}
\end{aligned}
$$

where $\kappa$ is the system's curvature (shown in Fig. 1h).

Generally, material constants involved in the Eq. (2) are already known for the substrate, but unknown for the bond coat due to the changing composition at high temperature. For this reason, we will measure the stress in the substrate, and then based on force balance, the stress in the bond coat at high temperatures can be obtained. In sum, detailed methodology is described below:

i. Preparing a bond coat/substrate sample, and measuring its thicknesses and elastic moduli, namely, $h_{\mathrm{bc}}, h_{\mathrm{s}}, E_{\mathrm{bc}}$, and $E_{\mathrm{s}}$.

ii. Heating the sample to high temperatures, and then quenching fast, so that the nonelastic strain in Eq. (13), $\varepsilon^{\text {ne,C }}$, can be negligible.

iii. Applying Eq. (15) to the substrate (i.e., $\varepsilon^{\mathrm{e}}=\varepsilon_{\mathrm{s}}^{\mathrm{e}}$ ), and rearranging that equation, viz.:

$$
\kappa^{\mathrm{ne}}=\kappa-\kappa^{\mathrm{e}}=\kappa-\varepsilon_{\mathrm{s}}^{\mathrm{e}} \cdot \frac{\mathrm{A}_{2}}{\left[\mathrm{~A}_{1}+(y-\delta) \mathrm{A}_{2}\right]}\left(-h_{\mathrm{s}} \leq y \leq 0\right)
$$

iv. On the right side of Eq. (16), all the variables' values are available. Specifically, the 
actual curvature of the quenched sample, $\kappa$, can be experimentally measured. The elastic strain of substrate, $\varepsilon_{\mathrm{s}}^{\mathrm{e}}$, can be measured by the X-ray, which is performed on its bottom surface. So $y$ is equal to $-h_{\mathrm{s}} . \delta, \mathrm{A}_{1}$ and $\mathrm{A}_{2}$ can be calculated by Eq.(6), (10) and (11), respectively. As a result, the left side of Eq. (16), the system's curvature induced by non-elastic strain, $\kappa^{\text {ne }}$, can be obtained.

v. The average non-elastic strain of the substrate at room temperature, $\varepsilon_{\mathrm{s}, \mathrm{av}}^{\mathrm{ne}}$, is a function of $\kappa^{\text {ne }}$, and can be calculated by:

$$
\varepsilon_{\mathrm{s}, \mathrm{av}}^{\mathrm{ne}}=\int_{0}^{-h_{\mathrm{s}}}(\delta-y) \kappa^{\mathrm{ne}} d y / h_{\mathrm{s}}=-\left(\delta+h_{\mathrm{s}} / 2\right) \kappa^{\mathrm{ne}}
$$

where the subscript "av" refers to the average value.

vi. Because the sample was fast quenched ( $\left.\varepsilon^{\mathrm{ne}, \mathrm{C}}=0\right)$, and according to Eq. (13), $\varepsilon_{\mathrm{s}, \mathrm{av}}^{\mathrm{ne}}=\varepsilon_{\mathrm{s}, \mathrm{av}}^{\mathrm{ne}, \mathrm{T}}$, which means that the non-elastic strain produced at high temperatures in the substrate is retained to the room temperature. Consequently, the substrate's nonelastic strain at high temperatures is equal to its creep strain $\left(\varepsilon_{\mathrm{s}, \mathrm{av}}^{\mathrm{ne}, \mathrm{T}}=\varepsilon_{\mathrm{s}}^{\mathrm{T}}\right)$.

vii. Identifying the specific form of the creep formula $\varepsilon_{\mathrm{s}}^{\mathrm{T}}\left(\sigma_{\mathrm{s}}^{\mathrm{T}}, t\right)$ (Eq. (2)) for the substrate. viii. Performing the isothermal treatments at high temperature. Obtain the average nonelastic strain in the substrate $\varepsilon_{\mathrm{s}, \mathrm{av}}^{\mathrm{ne}}$ (equal to the creep strain $\varepsilon_{\mathrm{s}}^{\mathrm{T}}$ ) for each isothermal treatment (refer to step iv). Fit the substrate's creep formula $\varepsilon_{\mathrm{s}}^{\mathrm{T}}\left(\sigma_{\mathrm{s}}^{\mathrm{T}}, t\right)$ using these $\varepsilon_{\mathrm{s}, \mathrm{av}}^{\mathrm{ne}}-t$ experimental data. Therefore, the specific value of $\sigma_{\mathrm{s}}^{\mathrm{T}}$, namely, the high temperature stress in the substrate, can be statistically determined.

ix. Lastly, the high temperature stress in bond coat, $\sigma_{\mathrm{bc}}^{\mathrm{T}}$, can be indirectly obtained through Eq. (1). 
In this study, we will employ this approach to measure the high temperature stress in the bond coat. A typical NiCoCrAlY bond coat with a Hastelloy-X substrate system, which is widely used in industrial gas turbine, was used as a model sample. First, the evolution of the curvature and the elastic stress in the substrate were measured as a function of heat exposure time. Then the stress in the bond coat was estimated based on above theory. In addition, the origination of the high temperature stress was discussed, and its effect on the roughening of the bond coat was also investigated.

\section{Experiment}

\subsection{Sample preparation and heat exposure}

The NiCoCrAlY (Ni-23Co-17Cr-12.5Al-0.6Y in wt.\%) bond coat was deposited by HVOF on a Hastelloy (Ni-22Cr-18Fe-9Mo-1.5W-0.10C in wt.\%) substrate $(55 \mathrm{~mm} \times 100 \mathrm{~mm} \times 4 \mathrm{~mm})$. The as-deposited bond coat is approximately $600 \mu \mathrm{m}$ thick, comprised of a mixture of $\beta$ (dark contrast) and $\gamma$ phases (bright contrast), as shown in Fig. 2a-b. Beam $(55 \mathrm{~mm} \times 4 \mathrm{~mm} \times 4 \mathrm{~mm})$ bond coat/substrate samples were cut and used for the curvature and the X-ray measurements. On a relatively thin substrate, the force contributed by the stress presented in the bond coat will easily cause the substrate to bend. The substrates were thinned using electro-spark cutting, grinded using 1500 grit papers and then polished. The final dimension of the sample was 55 $\mathrm{mm} \times 4 \mathrm{~mm} \times 2.1 \mathrm{~mm}$. Annealing was performed to eliminate the residual compressive stress introduced by the grinding and polishing processes. This was achieved by wrapping the samples with a Ti foil and sealing them in quartz tube in vacuum. The annealing was conducted in vacuum for $20 \mathrm{~h}$ at $800{ }^{\circ} \mathrm{C}$ and then cooled in furnace to room temperature. The selected temperature is high enough to relax the stresses, but low enough to prevent inter-diffusion [13]. 

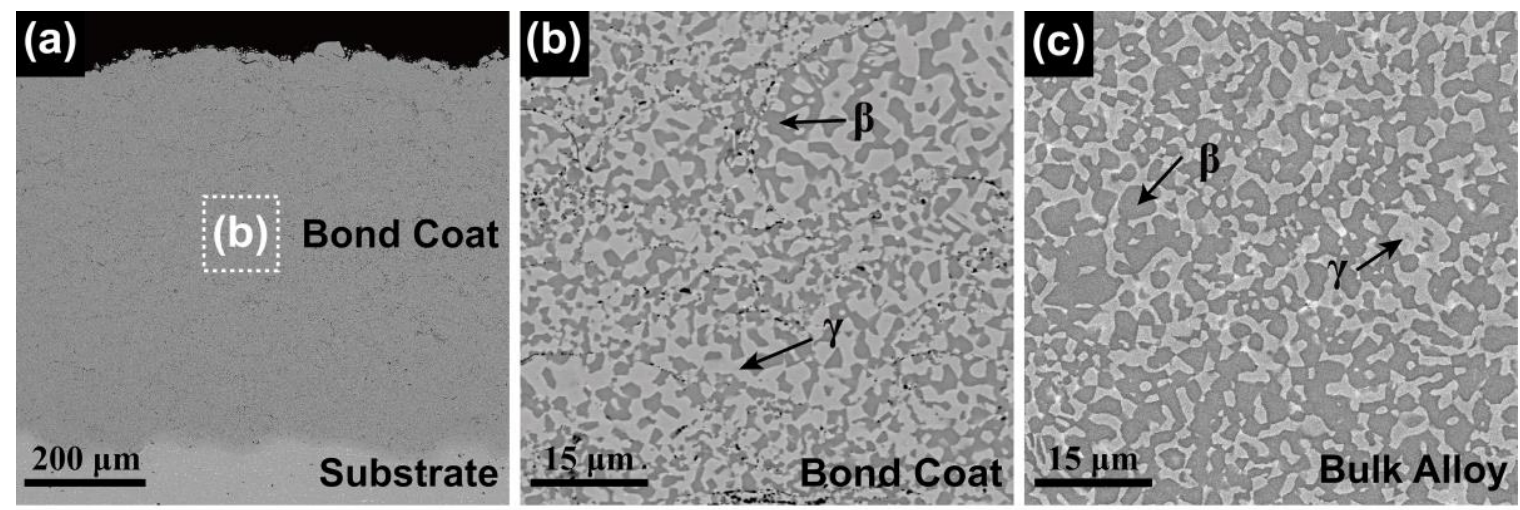

Fig. 2 (a) Scanning electron microscopy micrograph of the as-deposited bond coat; (b) enlarged view of the bond coat; (c) SEM micrograph of the as-sintered bulk NiCoCrAIY alloy. Both of the bond coat and bulk alloy consist of $\beta$ (gray contrast) and $\gamma$ (white contrast) phases.

To study the volume change of the bond coat and the substrate after heat exposure, rectangular $(10 \mathrm{~mm} \times 4 \mathrm{~mm} \times 2.1 \mathrm{~mm})$ bond coat/ substrate samples were also cut. The edges of the sample were grounded using grit papers. To compare the surface roughness of the bond coat with the bulk alloy, the bulk alloy with the same composition was prepared by spark plasma sintering (SPS, FCT-HP D25/4-SD). The NiCoCrAlY powder was first packed in a graphite die with an internal diameter of $28 \mathrm{~mm}$, and then separated by graphite paper and sintered at $1050{ }^{\circ} \mathrm{C}$ in vacuum (< $1 \mathrm{mbar})$ at a load of $50 \mathrm{MPa}$ for 10 minutes. As shown in Fig. 2c, the as-sintered bulk alloy is fully dense and also comprised of $\gamma$-phase (bright contrast) and $\beta$-phase (dark contrast). Disc samples (28 mm in diameter and $2.1 \mathrm{~mm}$ in thickness) were cut from the bulk alloy. The bulk alloy were grounded and polished. This produced a similar initial root-meansquare roughness $S_{\mathrm{q}}(\sim 0.01 \mu \mathrm{m})$ for all samples.

Isothermal test was carried out at $1150{ }^{\circ} \mathrm{C}$ in a chamber furnace in ambient air for different periods of time up to $120 \mathrm{~h}$. After isothermal treatment, the samples were cooled in liquid nitrogen to retain the samples' non-elastic deformation occurred at high temperature. 


\subsection{Microstructure and TEM characterization}

The cross-sectional microstructure of the sample was examined using scanning electron microscopy (SEM, FEI Quanta 200) operating in the back-scattered mode. Grain size of the substrate was evaluated using electron backscatter diffraction technology (EBSD, Zeiss Supra 55). Moreover, the EBSD measurement can obtain the information of the crystal orientation, which is used to verify whether the substrate is isotropic and the elastic properties of the substrate is uniform. Area maps were recorded at a minimum of five locations. EBSD data was analyzed by HKL Channel 5 software.

Phases of the bond coat and substrate are also characterized using the selected area electron diffraction (SAED) in transmission electron microscope (TEM). TEM cross-sectional samples of bond coat/substrate system were prepared via the cutting of disks $4 \mathrm{~mm} \times 2.1 \mathrm{~mm} \times 2 \mathrm{~mm}$ in dimension and mechanical polishing to a thickness of about $60 \mu \mathrm{m}$. The portions of the bond coat/substrate interface were reduced further to $\sim 10 \mu \mathrm{m}$ by mechanical dimpling (Model 656, Gatan Inc.) followed by final polishing. The final perforation of the sample was conducted via precision argon-ion milling (model 691, Gatan Inc.), using an acceleration voltage of $4 \mathrm{kV}$. TEM experiments were conducted using a Tecnai F30 G2 microscope (FEI) at $300 \mathrm{kV}$.

\section{3. $X$-ray $\sin ^{2} \Psi$ and curvature measurements}

In order to obtain the average non-elastic strain in the substrate $\left(\varepsilon_{\mathrm{s}, \mathrm{av}}^{\mathrm{ne}}\right)$ (as indicated in step iiiiv), the elastic strain of substrate $\left(\varepsilon_{\mathrm{s}}^{\mathrm{e}}\right)$ and the curvature of the sample $(\kappa)$ should be obtained in advance. $\varepsilon_{\mathrm{s}}^{\mathrm{e}}$ by the $\mathrm{X}$-ray $\sin ^{2} \Psi$ technique, and $\kappa$ can be measured by the curvature method. 
The X-ray $\sin ^{2} \Psi$ technique was carried out using a Proto iXRD system with a Mn $\mathrm{K}_{\alpha}$ radiation $\left(\lambda_{\mathrm{Mn}}=2.1031 \AA\right)$ on the bottom surface of the substrate in a bond coat/substrate sample, as the measurement geometry shows in Fig. 3. The diffraction peak from the (311) plane of $\gamma$ phase at the $2 \theta$ angle around $154^{\circ}$ was selected for measurements [10]. The twin detectors 1 and 2 in Fig. 3 captured the opposite sides of the diffraction cone, thus enabling two $\Psi$ offsets to be measured simultaneously. A $3^{\circ}$ oscillation in the $\beta$ angle was used at each tilt. Both position and width of the diffraction peaks were obtained by fitting the profile with Gaussian function. To eliminate the instrument background, a gain measurement was always made on a nondiffracting ferrite material before the measurements. A total of nine measurements with an equal interval along the length direction of each sample were performed.
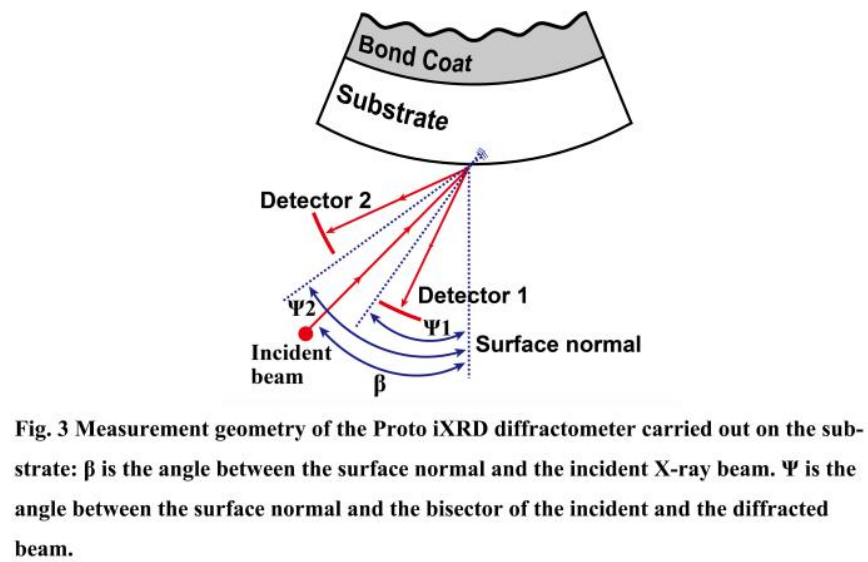

The curvature method was conducted using an optical microscope (BX51M Olympus). Specifically, the sample was placed under the lens and moved horizontally at $1 \mathrm{~mm}$ per time (X axis) and at each position, the sample surface was focused and the focus was recorded as the vertical height ( $\mathrm{Z}$ axis). The curvature of the sample can be obtained by fitting the $X-Z$ profile using a circle function [21]. To ensure reliability of the results, a 50× optical lens was employed and 50 measurements were performed for each sample. 


\subsection{Surface roughness measurement}

To study the effect of the high temperature stress on the surface roughness of the bond coat, the evolutions of surface roughness for the bond coat/substrate samples and the bulk alloys were detected using a profile-meter (ZeGage, Zygo). To avoid the effect of TGO layer on the surface roughness of bond coat, the TGO layer was removed prior to the surface roughness measurement. This was achieved by a dissolved method using a $\mathrm{NaOH}$ solution $(20 \mathrm{~mol} / \mathrm{L})$ at $200{ }^{\circ} \mathrm{C}$ for up to $24 \mathrm{~h}$. The rumpling magnitude was characterized by the root mean square roughness, $S_{\mathrm{q}}$. For each sample, at least 10 areas $(0.3 \mathrm{~mm} \times 0.3 \mathrm{~mm})$ were measured.

\section{Results}

\subsection{Microstructure evolution of the bond coat with heat exposure}

Fig. 4 shows the TEM bright field image and the corresponding SAED patterns of $\beta$ and $\gamma$ phases along the $[010]_{\beta}$ and the $[011]_{\gamma}$ orientations, respectively, in the as-deposited bond coat. The SAED pattern of $\beta$ phase reveals superlattice reflections which confirms the ordered state of the phase. But the SAED pattern of $\gamma$ phase reveals no superlattice reflection which also confirm that the disordered state of the phase and there is no order $\gamma^{\prime}$ phase formation in the bond coat. This suggests that no $\gamma^{\prime} \rightarrow \gamma$ order-disorder transformation happens during the heat exposure, where the transformation will be related to the volume change [22].

Fig. 5a and e show the cross-sectional SEM images of the as-deposited sample and the sample after heat exposure for $48 \mathrm{~h}$, respectively. Enlarged views are also illustrated on the right of the 

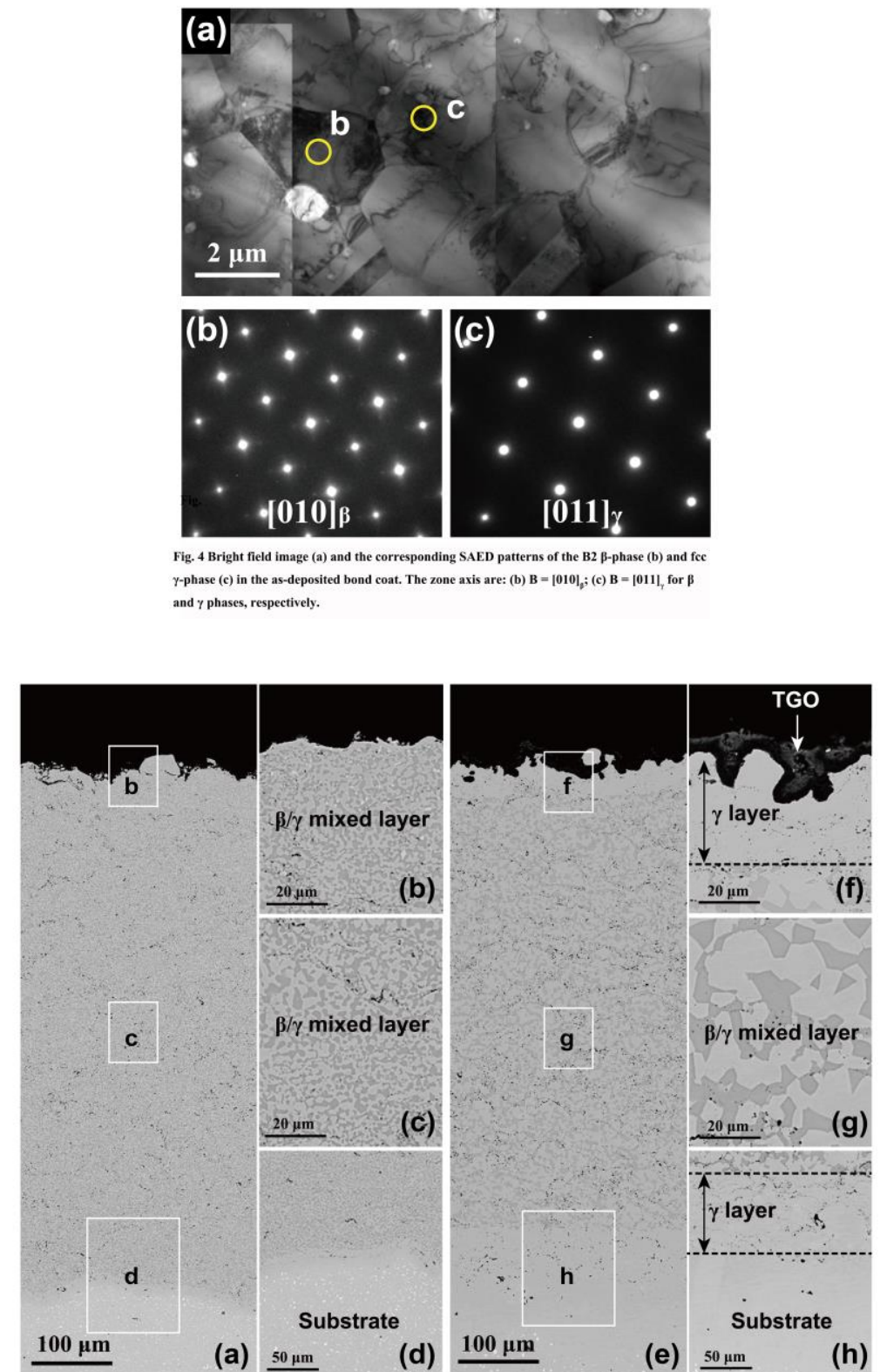

Fig. 5 Backscattered SEM micrographs of the bond coat cross-section after deposited (a) and heat exposure at $1150{ }^{\circ} \mathrm{C}$ for 48 $h$ (e). Enlarged views (b-d and $f-h$ ) of the designated areas are inserted on the right of the corresponding whole images. The heat exposed bond coat consisting of a $\gamma$ layer at the top, a $\beta / \gamma$ mixed layer in the middle and a $\gamma$ layer at the bottom.

corresponding images. The bond coat undergoes two changes after heat exposure. First, the homogeneous $\beta / \gamma$ mixed mono-layer changes to three layers: a $\gamma$ layer at the top, a $\beta / \gamma$ mixed layer and a $\gamma$ layer at the bottom. Second, grain sizes of the $\beta$ and $\gamma$ phases in the $\beta / \gamma$ mixed layer increase. Fig. 6 presents the volume fractions of $\beta$ and $\gamma$ phases in the bond coat as a function of heat exposure time, which were estimated based on the area fractions of each phase by processing the cross-sectional images of the coatings. The results show that the volume 
fraction of $\gamma$ phase increases with heat exposure time, whereas that of the $\beta$ phase shows an opposite trend because of the phase transformation from $\beta$ to $\gamma$ phase. The phase transformation occurs at high temperature because it is inhibited during the fast cooling. Plots of volume fractions of the $\beta$ and $\gamma$ phases in the bond coat versus heat exposure time, $t$, can be fitted using the following functions [23]:

$$
\begin{aligned}
& f_{\beta} \approx \mathrm{k}_{\beta} t^{\mathrm{m}_{\beta}}+f_{\beta 0} \\
& f_{\gamma} \approx \mathrm{k}_{\gamma} t^{\mathrm{m}_{\gamma}}+f_{\gamma 0}
\end{aligned}
$$

where the subscripts " $\beta$ " and " $\gamma$ " refer to the $\beta$ and $\gamma$ phases, respectively; $k$ and $m$ are constants depending on the heat exposure temperature; $f_{\beta 0}$ and $f_{\gamma 0}$ are the initial volume fractions of the $\beta$ and $\gamma$ phases, respectively. From fitting, the constants $m$ of the $\beta$ and $\gamma$ phases are about 0.56 and 0.60 , respectively. This suggests that the phase transformation is diffusion-controlled. The phase transformation might change the bond coat's volume and thus influence the high temperature stress in the bond coat. 


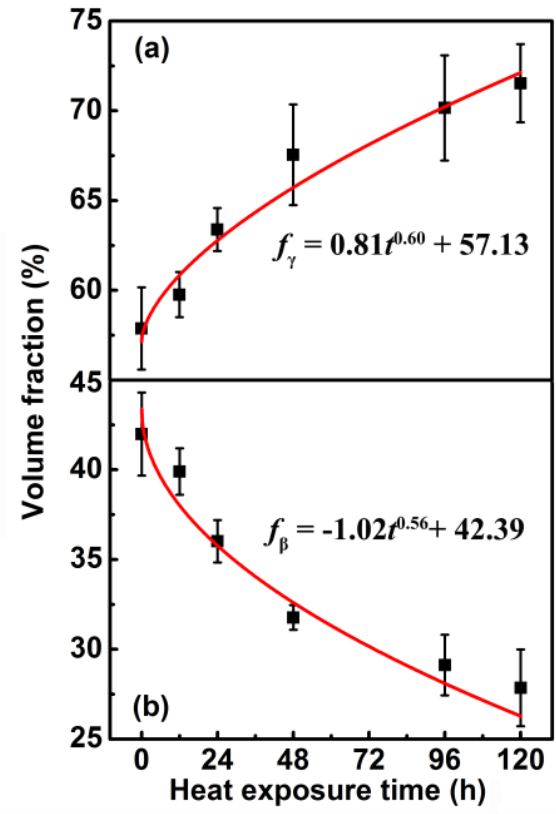

Fig. 6 Average volume fraction of (a) $\gamma$ and (b) $\beta$ phase as a function of heat exposure time.

4.2. Elastic strain of substrate evolution with heat exposure

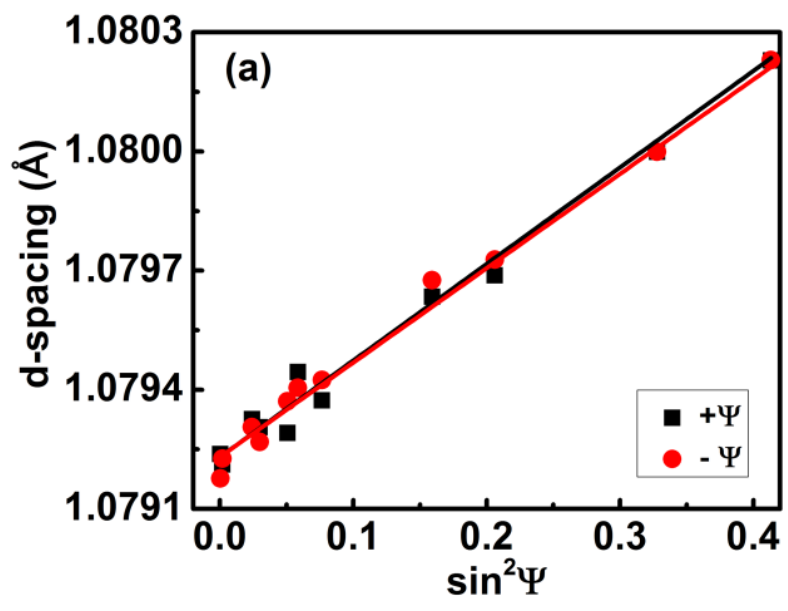




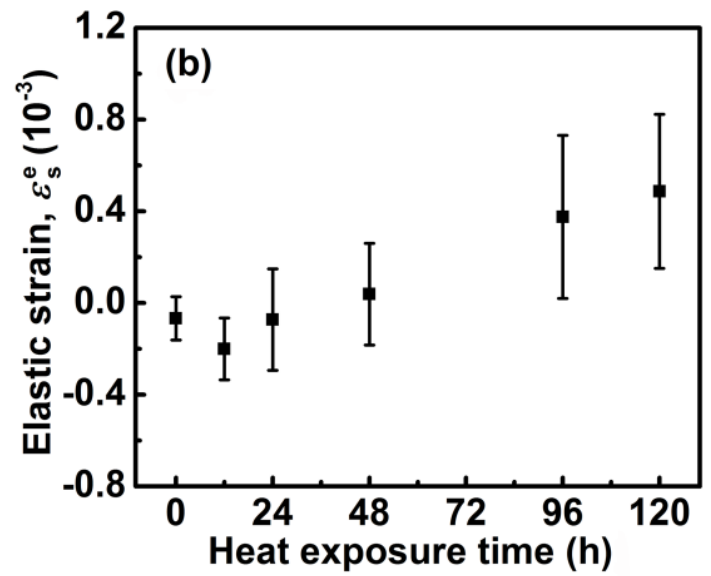

Fig. 7 (a) Typical example of the (311) plane spacing $d_{\Psi}$ as a function of $\sin ^{2} \Psi$ ( $\Psi$ is the tilting angle); (b) the elastic strain in the bottom of substrate, $\varepsilon_{s}^{\mathrm{e}}$, measured by the $\mathrm{X}$-ray $\sin ^{2} \Psi$ technique, as a function of heat exposure time.

Fig. 7a shows a typical example of the (311) plane spacing $d \Psi$ as a function of $\sin ^{2} \Psi$. The acquired $d \Psi-\sin ^{2} \Psi$ plots were fitted with a straight line. The well consistency of the two lines obtained from two tilting angles $(+\Psi$ and $-\Psi)$ indicates that the out-of-plane shear stresses and stress gradient in the X-ray sampling region are negligible. The elastic strain can be correlated with the slope by [10]:

$$
\varepsilon=\left(\frac{1}{1+v_{\mathrm{s}}}\right)_{(h k l)} \frac{1}{d_{n}} \frac{\left(d_{\Psi}-d_{n}\right)}{\sin ^{2} \Psi}
$$

where $d_{\mathrm{n}}$ is the interplanar spacing along the surface normal $(\Psi=0) . d_{\mathrm{n}}$ was estimated based on the (311) diffraction peak of the $\gamma$ phase. With Poisson's ratio of the substrate $v_{\mathrm{s}}(=0.31)$, the elastic strains in the bottom of the substrate, $\varepsilon_{\mathrm{s}}^{\mathrm{e}}\left(y=-h_{\mathrm{s}}\right)$ determined using Eq. (19) are shown in Fig. 7b. The strain evaluated by the X-ray only comes from the macro-stress, i.e., the elastic misfit between the bond coat and the substrate (See Appendix A for details). In asdeposited condition, the bottom surface of the substrate is under compression. After heat exposure, the compressive strain increases slightly after initial heat exposure. Further heat exposure changes the compressive stress to tensile, and then the tensile stress gradually 
increases. The analysis on this elastic strain evolution with heat exposure is also presented in Appendix A.

\subsection{Curvature evolution with heat exposure}

Fig. 8a presents the cross-sectional SEM images of the as-deposited sample (I) and $48 \mathrm{~h}$ heatexposed sample (II). The corresponding 2-D circle fitting profiles (curvature curves) are shown in Fig. 8b. For both samples, the bond coat is always on the concave side, and the curvature of the bond coat on the concave side is defined to be positive. The sample bends more after heat exposure for $48 \mathrm{~h}$. The evolution of curvature $(\kappa)$ with heat exposure time is presented in Fig. 8c. It can be seen that the curvature is positive in as-deposited condition and increases with the heat exposure time. The curvature indicates that the total strain of the system increases with heat exposure. Then based on the measured elastic strains in the bottom of substrate, the curvatures of the system and the Eq. (5), the curvatures induced by elastic strain, $\kappa^{\mathrm{e}}$, and nonelastic strain, $\kappa^{\text {ne }}$, as a function of heat exposure time are calculated and shown in Fig. 8d. 


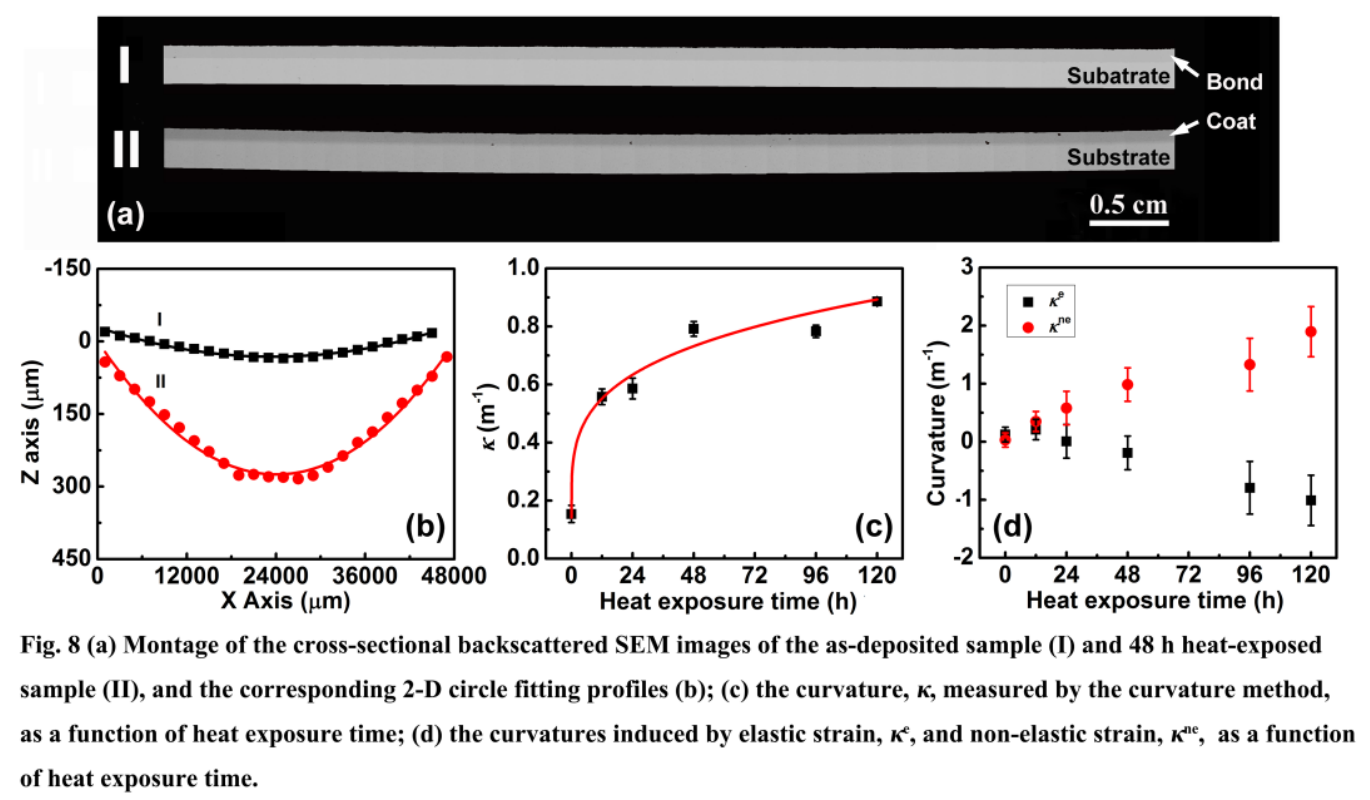

\section{Discussion}

\subsection{The origin of high temperature stress in the NiCoCrAlY bond coat}

It has been demonstrated that, during high temperature exposure, the $\beta$ phase gradually transformed to $\gamma$ phase (Fig. 6), which induced by the TGO growth and the inter-diffusion with the substrate [10]. The $\beta-\gamma$ phase transformation involves a volume shrinkage up to $38 \%$ [24]. To illustrate such volume shrinkage, the cross-sectional images around the sample edge were taken. As shown in Fig.9, with an increase of the time, the edge gradually shrinks, especially the $\gamma$ layer at the bottom region of bond coat (the inter-diffusion layer).

The observation is further confirmed by the corresponding edge profile in Fig. 9d. The horizontal dashed line presents the bond coat/substrate interface while the vertical gray dashed lines refer to the initial edges. The profiles clearly show that: 1) the edge of the bond coat progressively decreases as the exposure time increases; 2) the edge close to the coat/substrate interface, namely $\gamma$ layer at the bottom of bond coat and the inter-diffusion layer of the substrate, shrinks more as the exposure time increases. Since the inter-diffusion zone of the substrate is 
much thinner than the bond coat, the influence of this zone on the high temperature stress can be neglected. Therefore, the high temperature stress in the bond coat is mainly caused by the volume change of bond coat due to the $\beta-\gamma$ phase transformation.

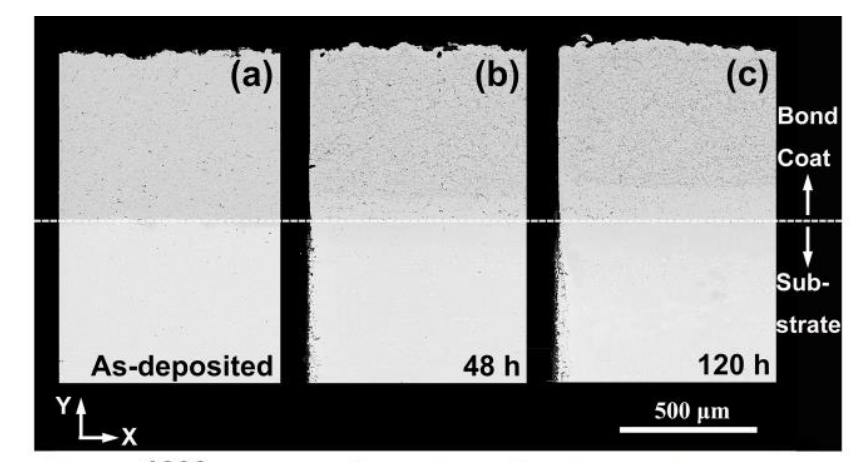

(d)

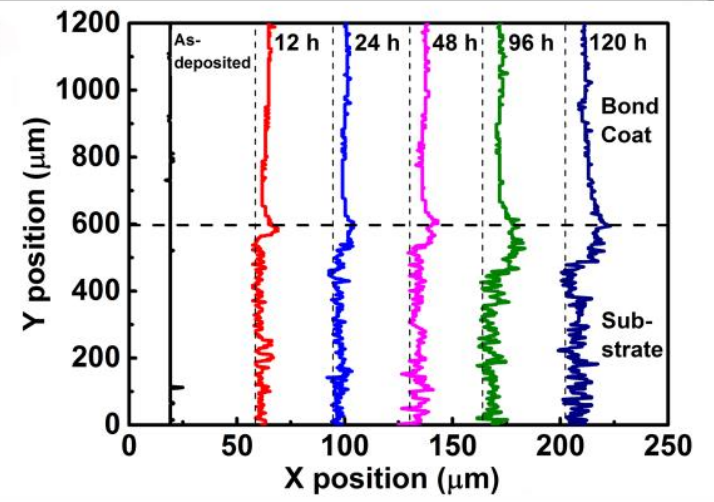

Fig. 9 Backscattered SEM micrographs of the cross-sectional sides of the as-deposited (a), 48 (b), and $120 \mathrm{~h}$ (c) heat-exposed samples and (d) profiles of the left side edge of the samples with different exposure times. The vertical gray dashed lines refer to the initial edges while the horizontal dashed line presents the bond coat substrate interface. The overall bond coat and the coat/substrate interface shrink with heat exposure.

\subsection{Determination of the high temperature stress}

As indicated in the steps iii-v, provided that the elastic strain in the bottom of substrate (Fig. 7) and the curvature (Fig. 8) are known, the system's curvature induced by non-elastic strain can be calculated. The influence of the TGO can be neglected since it was removed using $\mathrm{NaOH}$ solution. In the calculations, the elastic moduli of the bond coat and the substrate are listed in Table $1[25,26]$. According to Eq.(17), the creep strain $\left(\varepsilon_{\mathrm{s}}^{\mathrm{T}}\right)$ are obtained and plotted in Fig. 10. It can be seen that the compressive creep strain of substrate increases with heat exposure time. 


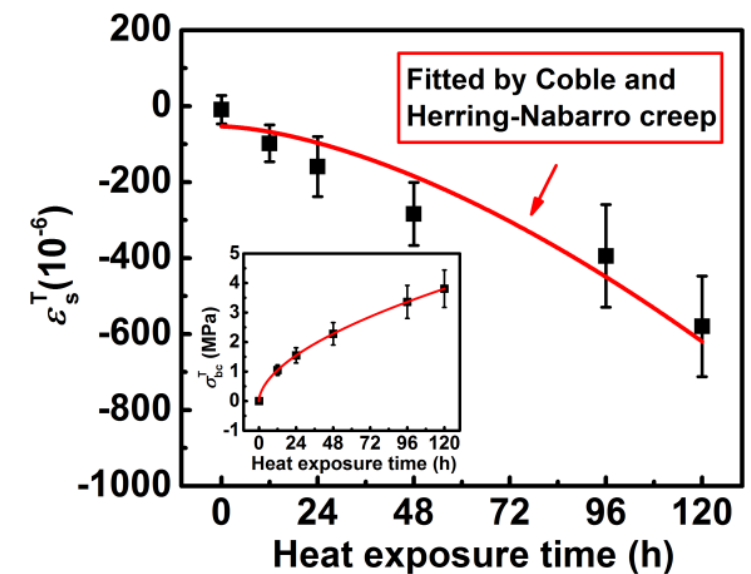

Fig. 10 Relationship between the average creep strain of substrate, $\varepsilon_{s}^{\mathrm{T}}$, and the heat exposure time. The line drawn through the creep strain data is the best fit using the Coble and Herring-Nabarro creep equation. The inset is the high temperature stress in the bond coat, $\sigma_{\mathrm{bc}}^{\mathrm{T}}$, versus heat exposure time obtained from fitting.

The creep strain of the substrate is about $-6 \times 10^{-4}$ after heat exposure for $120 \mathrm{~h}$ (Fig.10). Since the $\beta$ to $\gamma$ phase transformation results in a volume shrinkage of $\sim 38 \%$ [24], the strain in one direction, $\Delta \varepsilon_{\beta-\gamma}$, is about $-15 \%$. Hence the average strain induced by the phase transformation for $120 \mathrm{~h}$ is about $\Delta f_{\beta} \Delta \varepsilon_{\beta-\gamma}=15 \% \times(-15 \%)=-0.0225$, where $\Delta f_{\beta}$ is the volume fraction change of $\beta$ phase (about $15 \%$ from Fig. 6). It can be seen that the strain rate induced by the phase transformation is much larger than the strain rate induced by the creep, which implies that stress generation in the bond coat is much faster than the stress relaxation. Therefore, the stress in the bond coat is dominated by the phase transformation, which is proportional to the volume fraction change. The stress in the substrate $\left(\sigma_{\mathrm{s}}^{\mathrm{T}}\right)$ can be expressed:

$$
\sigma_{\mathrm{s}}^{\mathrm{T}}=\mathrm{k} \Delta f_{\beta}=\mathrm{k}\left(\mathrm{k}_{\beta} t^{\mathrm{m}_{\beta}}\right)=\mathrm{k}_{\mathrm{s}} t^{\mathrm{m}_{\beta}}
$$

where $\mathrm{k}$ and $\mathrm{k}_{\mathrm{s}}$ are constants. This equation will be substituted into the creep equation $\varepsilon_{\mathrm{s}}^{\mathrm{T}}\left(\sigma_{\mathrm{s}}^{\mathrm{T}}, t\right)$

If the creep of the substrate follows the dislocation creep mechanism, i.e., Norton's law [27]: 


$$
\dot{\varepsilon}_{\mathrm{s}}^{\mathrm{T}}=\frac{\mathrm{B} G^{1-n} \mathrm{~b}_{\mathrm{v}} D_{\mathrm{v}}}{\mathrm{k}_{\mathrm{B}} T}\left(\sigma_{\mathrm{s}}^{\mathrm{T}}\right)^{n}
$$

where $n$ is the stress exponent, which does not change with stress at a constant temperature; $\mathrm{k}_{\mathrm{B}}$ is the Boltzmann constant; and

$$
D_{\mathrm{v}}=D_{\mathrm{v} 0} \exp \left(-Q_{\mathrm{v}} / \mathrm{R} T\right)
$$

Since that the stress as a function of time has been obtained (Eq. (20)), the creep strain of the substrate can be written by:

$$
\varepsilon_{\mathrm{s}}^{\mathrm{T}}=\int \frac{\mathrm{B} G^{1-n} \mathrm{~b}_{\mathrm{v}} D_{\mathrm{v}}}{\mathrm{k}_{\mathrm{B}} T}\left(\mathrm{k}_{\mathrm{s}} t^{\mathrm{m}_{\beta}}\right)^{n} d t
$$

Subsequently, the constant $\left(\mathrm{k}_{\mathrm{s}}\right)$ can be obtained from fitting the creep strain-time data using Eq. (23), and the material parameters are summarized in Table 1 [27]. Finally the stress in the substrate at the high temperature $\left(\sigma_{\mathrm{s}}^{\mathrm{T}}\right)$ is obtained using Eq. (20) and the stress exponent $(n)$ is 0.34. It was reported that $\mathrm{n}$ should be $>3$ under dislocation creep $[28,29]$. This indicates that the substrate would be subjected to the diffusional creep (Coble and Herring-Nabarro creep) rather than the dislocation creep.

To discuss the creep mechanism of the substrate, a creep mechanism map of the pure nickel for a grain size of $100 \mu \mathrm{m}[17,30]$ has been employed, due to lack of the data on the Hastelloy-X at $1150{ }^{\circ} \mathrm{C}$. This map shows that Coble creep is in the lower part of temperature range $\left(\mathrm{T} / \mathrm{T}_{\mathrm{m}}<\right.$ $0.8)$, and Herring-Nabarro in the upper part $\left(\mathrm{T} / \mathrm{T}_{\mathrm{m}}>0.8\right)$. The heat exposure temperature and the melting point in this study are $1423 \mathrm{~K}$ and $1726 \mathrm{~K}$ [26], respectively, therefore $\mathrm{T} / \mathrm{T}_{\mathrm{m}}$ is 
larger than 0.8. In addition, the grain size of substrate is $\sim 300 \mu \mathrm{m}$ measured by EBSD (Appendix B), which is larger than the pure nickel in the map $(100 \mu \mathrm{m})$. With an increase in the grain size, the Herring-Nabarro creep occurs more easily [17]. Therefore, the substrate was subjected to both Coble and Herring-Nabarro creep.

The creep strain $\left(\varepsilon_{\mathrm{s}}^{\mathrm{T}}\right)$ in the both Coble and Herring-Nabarro regime can be expressed as [29]:

$$
\varepsilon_{\mathrm{s}}^{\mathrm{T}}=\int \frac{14.3 \Omega \sigma_{\mathrm{s}}^{\mathrm{T}} D_{\text {eff }}}{\mathrm{k}_{\mathrm{B}} T d^{2}} d t
$$

where the effective diffusion coefficient, $D_{\text {eff }}$, is presented by:

$$
D_{\text {eff }}=D_{\mathrm{v}}\left[1+\left(\frac{\pi}{d}\right)\left(\frac{D_{\mathrm{gb}}}{D_{\mathrm{v}}}\right)\right]
$$

with

$$
D_{\mathrm{gb}}=D_{\mathrm{gb} 0} \exp \left(-Q_{\mathrm{b}} / \mathrm{R} T\right)
$$

and $d$ is the grain size of substrate (around $300 \mu \mathrm{m}$ ). Then, the creep strain-time data (Fig. 10) was fitted using the Eq. (24). From fitting, the constant $\left(\mathrm{k}_{\mathrm{s}}\right)$ is obtained as $-0.12 \pm 0.02$, and the high temperature stress in the bond coat $\sigma_{\mathrm{bc}}^{\mathrm{T}}$ is $1.05 \mathrm{MPa}$ at $12 \mathrm{~h}$ and increases parabolically to about 3.81 MPa after $120 \mathrm{~h}$ exposure, as Fig. 10(inset) shows. The high temperature stresses are agreement with those measured by X-ray [10].

\subsection{Effect of high temperature stress on the surface rumpling}

Fig. 11a presents the surface roughness of the bond coat $\left(S_{\mathrm{q}, \mathrm{bc}}\right)$ and the bulk alloy $\left(S_{\mathrm{q}, \mathrm{a}}\right)$ with different heat exposure times. In contrast to the bond coat, the bulk alloy shows a much smaller 
roughness increase under the same condition, which is in agreement with the previous studies [23]. To elucidate the role of the bond coat stress, the surface roughness $\left(S_{\mathrm{q}, \mathrm{bc}}\right)$ is correlated with the stress $\left(\sigma_{\mathrm{bc}}^{\mathrm{T}}\right)$ at high temperature, as shown in Fig. 11b. It is evident that the surface roughness increases near-linearly with the tensile stress in the bond coat. This finding indicates that the high temperature stress in the bond coat might be the dominant factor for the surface rumpling.
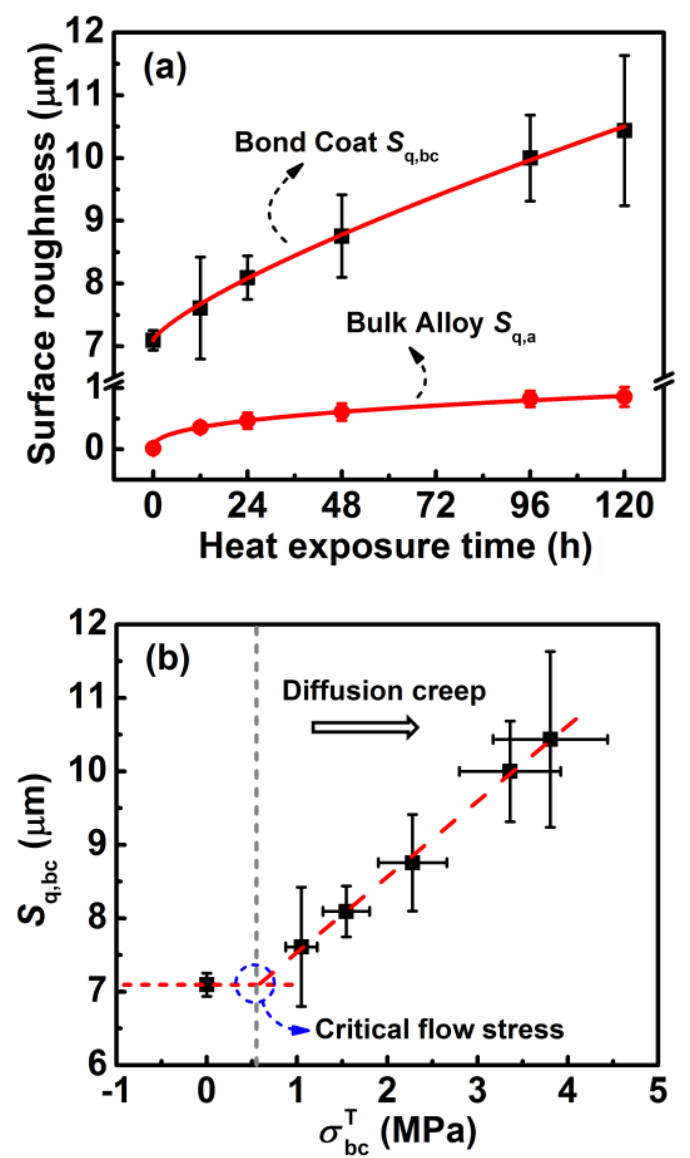

Fig. 11 (a) The surface roughnesses of the NiCoCrAIY bond coat, $S_{q, b e}$, and the bulk NiCoCrAIY alloy, $S_{q, a}$, as a function of heat exposure time at $1150{ }^{\circ} \mathrm{C}$. (b) Relationship between the high temperature stress in the bond coat, $S_{\text {q.be }}$, and the surface roughness of the NiCoCrAIY bond coat, $\sigma_{\mathrm{bc}}^{\mathrm{T}}$.

Nychka et al. proposed that the grain sliding in the bond coat at high temperature occurs in response to the compressive growth stress in the TGO, namely tensile stress in the bond coat due to the force balance [18]. On the basis of the stress results in this study, the bond coat stress- 
driven surface rumpling mechanism can be proposed: at high temperature, when the stress in the bond coat exceeds a critical flow stress, the grain sliding occurs and grains will move relative to one another with surface uplifts, leading to the surface roughening macroscopically. It is worth noting that such mechanism is universal, whether the high temperature stress in the bond coat is compressive (induced by volume swell), or tensile (induced by volume shrinkage). Schematic of the surface rumpling mechanism is shown in Fig. 12. The critical flow stress for the bond coat can be inferred by the surface roughness-high temperature stress plots (Fig. 11b) and is about $0.5 \mathrm{MPa}$, which is the minimum stress to active the grain sliding. The mechanism can be used to explain the surface rumpling behaviors of other two typical bond coats:

1) Pt- $\gamma / \gamma^{\prime}$ diffusion bond coat:

The bond coat consists of a two phase $\gamma$ and $\gamma^{\prime}$ microstructure and exhibits a comparable strength with the superalloy substrate at high temperature [31, 32]. In addition, it has been found that the high temperature stress in this bond coat is close to zero (e.g., $1150^{\circ} \mathrm{C}$ ), due to the low stress and high creep resistance, the rumpling of this type of bond coat is negligible compared with $\beta$ phase based bond coat $[31,32]$.

2) $\beta-(\mathrm{Pt}, \mathrm{Ni}) \mathrm{Al}$ bond coat:

Such bond coat exhibits a significant volume change due to the progressive phase transformation from the as-deposited single phase $\beta$ to a two phase $\beta+\gamma^{\prime}$ microstructure and the inter-diffusion of elements after oxidation $[18,24]$. This volume change leads to a significantly large stress. Since the $\beta$-(Pt, Ni)Al has a much lower resistant to plastic 
deformation than the Pt- $\gamma / \gamma^{\prime}$ bond coat at high temperature (e.g., $>750{ }^{\circ} \mathrm{C}$ ). Therefore, under the high temperature stress, the $\beta-(\mathrm{Pt}, \mathrm{Ni}) \mathrm{Al}$ bond coat exhibits an intense roughening [18].

Compared with the $\beta$-(Pt, Ni)Al bond coat, although NiCoCrAlY has a lower resistance [33], the interdiffusion between the bond coat and the substrate is less than the $\beta$-(Pt, Ni)Al. It might have a lower stress at high temperature and thus a smaller surface roughening.

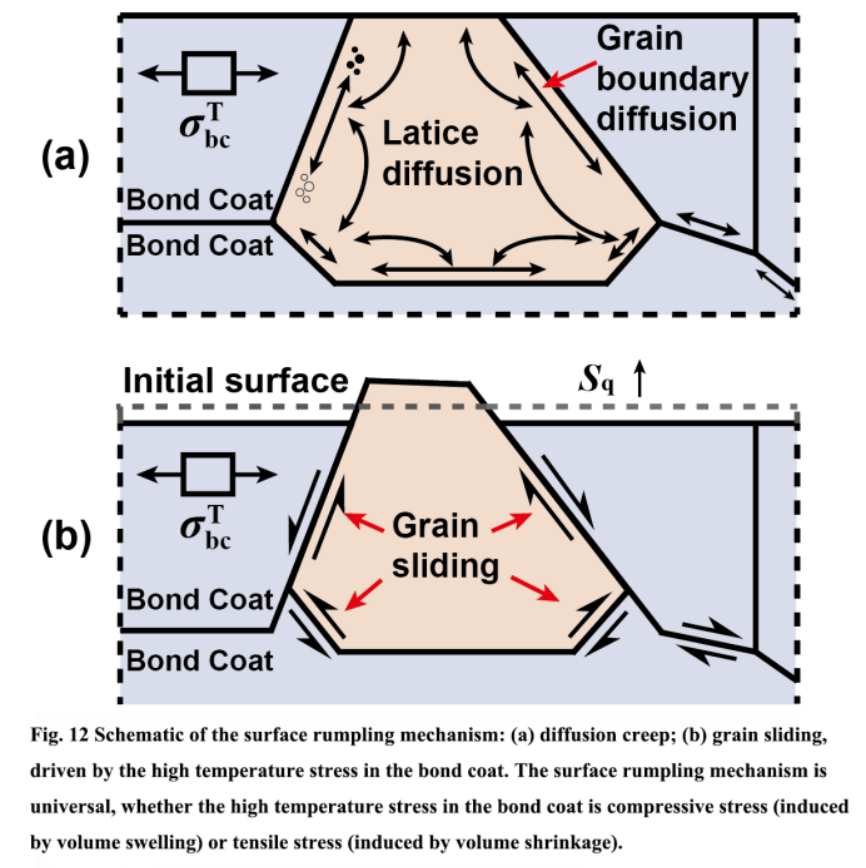

\section{Conclusions}

This work has developed an analytical model to evaluate the high temperature stress in the bond coat. Main findings are summarized as follows:

The methodology for estimating the bond coat high temperature stress includes the following steps:

i. Preparing a bond coat/substrate sample first, performing the heat exposure, and then quenching the sample after required heat exposure; 
ii. Measuring the curvature of the sample using the curvature method and the elastic strain of substrate using the X-ray $\sin ^{2} \Psi$ method;

iii. Calculating the average creep strain of the substrate, obtaining the creep strain-time data;

iv. Identifying the creep mechanism of the substrate, and using a proper equation to fit the creep strain-time data to determine the high temperature stress in the substrate. Then the bond coat stress at high temperature can be calculated based on force balance.

Employing this methodology, the high temperature stress in NiCoCrAlY bond coat on Hastelloy-X substrate was investigated. The stress was induced by the volume shrinkage of the bond coat as a result of $\beta-\gamma$ phase transformation, which is mainly due to the inter-diffusion between the bond coat and the substrate. It was found that the bond coat at high temperature was under tension, increasing from $1.05 \mathrm{MPa}$ after $12 \mathrm{~h}$ to $3.81 \mathrm{MPa}$ after $120 \mathrm{~h}$ at $1150{ }^{\circ} \mathrm{C}$.

The bond coat surface progressively roughened with heat exposure. In contrast, a bulk alloy with the same composition exhibited a much smaller roughness increase under the same treatment, suggesting the stress in the bond coat, mainly due to the inter-diffusion, played a dominant role on the surface rumpling.

The surface rumpling of bond coat exhibited a near-linear increase with the high temperature stress in the bond coat. It was proposed that the grain sliding in response to the high temperature stress in the bond coat is the dominant factor for the surface roughening. A critical stress is required to activate the grain sliding, which is about $0.5 \mathrm{MPa}$ for NiCoCrAlY bond coat on Hastelloy substrate studied in this work. 


\section{Acknowledgments}

The authors are grateful to Siemens for providing the samples and thank the financial support

from the National Natural Science Foundation of China (Nos.51271120 and 51402058), and the fund of Shanghai Committee of Science and Technology (No. 14ZR1422900). 


\section{Appendix A. Origin and analysis of the elastic strain evaluated by X-ray}

The elastic strains obtained by the X-ray $\sin ^{2} \Psi$ method could consist of macro- and microstrains for multi-phase materials, as previous showed $[10,32]$. Therefore, it is necessary to identify the phase composition of the substrate. Fig. A.1 shows the montage of TEM bright field image of the substrate and the corresponding SAED pattern along the [100]-orientation. The TEM image reveals the fcc matrix ( $\gamma$ phase) free of any precipitates in the substrate. Therefore, the strains measured by X-ray only consist of the macro-strain induced by the elastic misfit between the bond coat and the substrate.

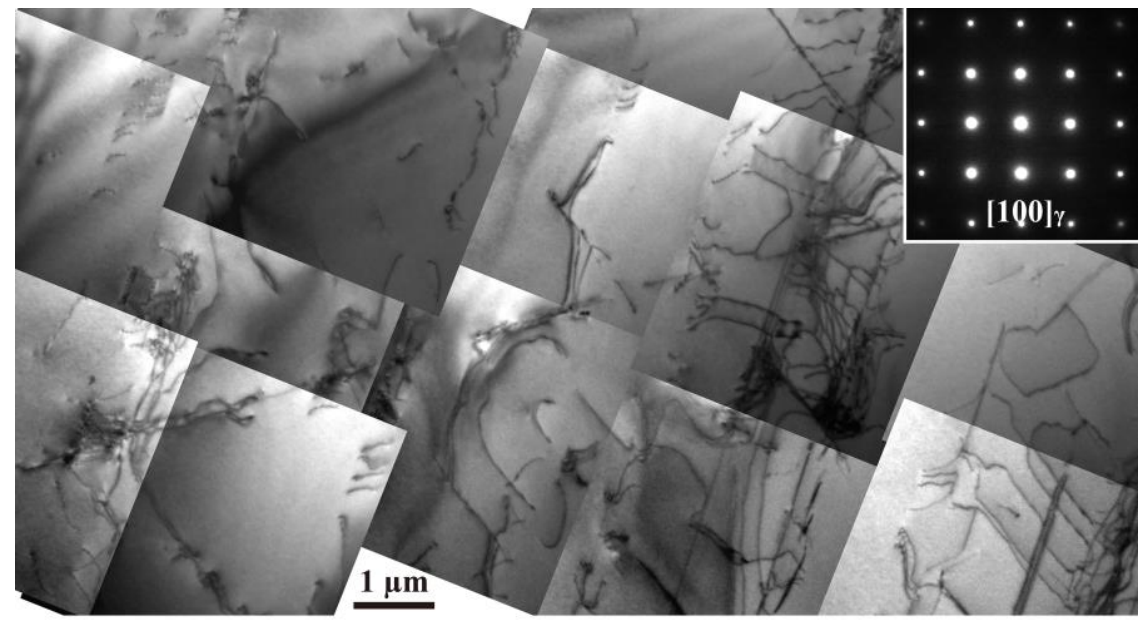

Fig. A.1 Montage of TEM images of substrate showing the only $\gamma$ phase in the substrate. The inset is the SAED patterns of the $\gamma$-phase. The zone axis is: $B=[100]_{\gamma^{*}}$

The measured elastic strain in the bottom of substrate comes from two sources: 1) the residual high temperature strain after cooling process, and 2) the thermal mismatch strain between the bond coat and the substrate. In addition, the elastic strain can also decompose a uniform and a bending component according to the Eq. (4). The compressive elastic strain in the bottom of substrate in as-deposited condition results from the thermal mismatch between 25 to $800{ }^{\circ} \mathrm{C}$. The compressive strains after heat exposure for 12 and $24 \mathrm{~h}$, are the combined action of the residual compressive high temperature strain and tensile thermal mismatch between 25 to 
$1150{ }^{\circ} \mathrm{C}$. After $24 \mathrm{~h}$, the increase in tensile strain is caused by the thermal mismatch and the increasing bending component of strain due to the increase in curvature (Fig. 8). A full discussion about the strain evolution is beyond the scope of this report.

\section{Appendix B. Determination of the grain size of substrate using EBSD}

EBSD maps were used in this study to measure the grain size of substrate and obtain the crystal orientation. Since the samples were cooled in liquid-nitrogen, no grain growth occurs during the temperature drop. Fig. B.1a shows the typical EBSD maps of substrate after heat exposure for $12 \mathrm{~h}$. From the EBSD maps, the grain size of substrate is not uniform and varies from 50 $\mu \mathrm{m}$ up to an approximately $400 \mu \mathrm{m}$. The average grain size is around $300 \mu \mathrm{m}$. There is no obvious change in the grain size with heat exposure. The $\{100\},\{110\}$ and $\{111\}$ normalized pole figures are given in Fig. B.1b-d. No crystallographic texture was observed from these figures, indicating that the substrate is isotropic and the elastic properties of the substrate is uniform.

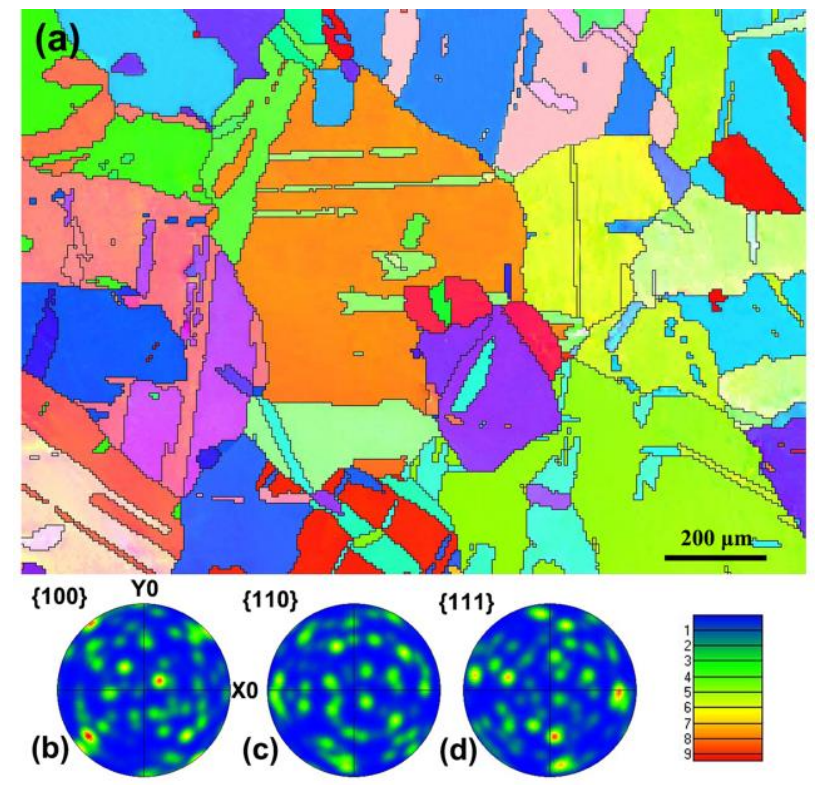

Fig. B.1 (a) Typical EBSD maps of the liquid-nitrogen quenched substrate after heat exposure for $12 \mathrm{~h}$. (b-d) $\{100\},\{110\}$ and $\{111\}$ normalized pole figures. 


\section{References}

[1] A.G. Evans, D.R. Mumm, J.W. Hutchinson, G.H. Meier, F.S. Pettit, Mechanisms controlling the durability of thermal barrier coatings, Prog. Mater. Sci. 46 (2001) 505-553.

[2] X. Zhao, P. Xiao, Thermal Barrier Coatings on Nickel Superalloy Substrates, Adv. Ceram. Mater. 606 (2008) 1-26.

[3] N.P. Padture, M. Gell, E.H. Jordan, Materials science - Thermal barrier coatings for gas-turbine engine applications, Sci. 296 (2002) 280-284.

[4] D. Balint, J. Hutchinson, An analytical model of rumpling in thermal barrier coatings, J. Mech. Phys. Solids 53 (2005) 949-973.

[5] A.M. Karlsson, C. Levi, A. Evans, A model study of displacement instabilities during cyclic oxidation, Acta Mater. 50 (2002) 1263-1273.

[6] K. Hemker, B. Mendis, C. Eberl, Characterizing the microstructure and mechanical behavior of a twophase NiCoCrAlY bond coat for thermal barrier systems, Mater. Sci. Eng. A 483 (2008) 727-730.

[7] V.K. Tolpygo, D. Clarke, On the rumpling mechanism in nickel-aluminide coatings: Part I: an experimental assessment, Acta Mater. 52 (2004) 5115-5127.

[8] M.W. Chen, R.T. Ott, T.C. Hufnagel, P.K. Wright, K.J. Hemker, Microstructural evolution of platinum modified nickel aluminide bond coat during thermal cycling, Surf. Coat. Technol. 163-164 (2003) 25-30.

[9] V. Tolpygo, D. Clarke, Rumpling of CVD (Ni, Pt) Al diffusion coatings under intermediate temperature cycling, Surf. Coat. Technol. 203 (2009) 3278-3285.

[10] Y. Chen, X. Zhao, Y. Dang, P. Xiao, N. Curry, N. Markocsan, P. Nylen, Characterization and understanding of residual stresses in a NiCoCrAlY bond coat for thermal barrier coating application, Acta Mater. 94 (2015) 1-14.

[11] T.M. Pollock, D.M. Lipkin, K.J. Hemker, Multifunctional coating interlayers for thermal-barrier systems, MRS Bull. 37 (2012) 923-931.

[12] M.E. Fitzpatrick, A.T. Fry, P. Holdway, F.A. Kandil, J. Shackleton, L. Suominen, Determination of Residual Stresses by X-ray Diffraction, National Physical Laboratory, Middlesex (2002).

[13] M. Watanabe, D.R. Mumm, S. Chiras, A.G. Evans, Measurement of the residual stress in a Pt-aluminide bond coat, Scr. Mater. 46 (2002) 67-70.

[14] S. Kuroda, T. Dendo, S. Kitahara, Quenching Stress in Plasma Sprayed Coatings and Its Correlation with the Deposit Microstructure, J. Therm. Spray Technol. 4 (1995) 75-84.

[15] A.G. Evans, D.R. Mumm, J.W. Hutchinson, G.H. Meier, F.S. Pettit, Mechanisms controlling the durability of thermal barrier coatings, Prog. Mater. Sci. 46 (2001) 505-553.

[16] W.-G. Kim, S.-N. Yin, Y.-W. Kim, J.-H. Chang, Creep characterization of a Ni-based Hastelloy-X alloy by using theta projection method, Eng. Fract. Mech. 75 (2008) 4985-4995.

[17] D. François, A. Pineau, A. Zaoui, Mechanical Behaviour of Materials: Volume I: Micro- And Macroscopic Constitutive Behaviour, Solid Mech. Appl. (2012).

[18] J.A. Nychka, C. Pullen, M.Y. He, D.R. Clarke, Surface oxide cracking associated with oxidationinduced grain boundary sliding in the underlying alloy, Acta Mater. 52 (2004) 1097-1105.

[19] S.P. Timoshenko, J.M. Gere, Theory of elastic stability, Courier Corporation (2009).

[20] S. Timoshenko, J. Gere, Mechanics of Materials. van Nordstrand Reinhold Company, New York, DOI (1972).

[21] L. Yang, F. Yang, Y. Long, Y. Zhao, X. Xiong, X. Zhao, P. Xiao, Evolution of residual stress in air plasma sprayed yttria stabilised zirconia thermal barrier coatings after isothermal treatment, Surf. Coat. 
Technol. 251 (2014) 98-105.

[22] T. Rehfeldt, G. Schumacher, R. Vasen, R.P. Wahi, Order-disorder transformation in a NiCoCrAlY bond coat alloy at high temperature, Scr. Mater. 43 (2000) 963-968.

[23] Y. Chen, X. Zhao, M. Bai, L. Yang, C. Li, L. Wang, J. Carr, P. Xiao, A mechanistic understanding on rumpling of a NiCoCrAlY bond coat for thermal barrier coating applications, Acta Mater. 128 (2017) 31-42. [24] V. Tolpygo, D. Clarke, Surface rumpling of a (Ni, Pt) Al bond coat induced by cyclic oxidation, Acta Mater. 48 (2000) 3283-3293.

[25] M. Hasegawa, Y. Kagawa, Microstructural and Mechanical Properties Changes of a NiCoCrAlY Bond Coat with Heat Exposure Time in Air Plasma-Sprayed Y2O3-ZrO2 TBC Systems, Int. J. Appl. Ceram. Technol. 3 (2006) 293-301.

[26] C.A. Rajesh, P.N. Parrikar, S. Abotula, A. Shukla, Effect of Boundary Conditions on the ThermoMechanical Response of Hastelloy® X Plates Subjected to Shock Loading, Dyn. Behav. Mater. 1 (2015) 301-305.

[27] A. Kikuchi, I. O'Donnell, Creep Fracture in Hastelloy XR, ICF8, Kiev (Ukraine) 1993, 2013.

[28] Y. Kurata, Y. Ogawa, T. Suzuki, M. Shindo, H. Nakajima, T. Kondo, Evaluation of long-term creep properties of hastelloy XR in simulated high-temperature gas-cooled reactor helium, DOI (1996).

[29] J.D. DeFouw, D.C. Dunand, Processing and compressive creep of cast replicated IN792 Ni-base superalloy foams, Mater. Sci. Eng. A 558 (2012) 129-133.

[30] H. Frost, M. Ashby, Deformation-mechanism maps, Pergamon, Oxford (1982).

[31] R.T. Wu, X. Wang, A. Atkinson, On the interfacial degradation mechanisms of thermal barrier coating systems: Effects of bond coat composition, Acta Mater. 58 (2010) 5578-5585.

[32] X. Zhao, B. Cernik, C.C. Tang, S.P. Thompson, P. Xiao, Stress evolution in a Pt-diffused $\gamma / \gamma^{\prime}$ bond coat after oxidation, Surf. Coat. Technol. 247 (2014) 48-54.

[33] D. Pan, M.W. Chen, P.K. Wright, K.J. Hemker, Evolution of a diffusion aluminide bond coat for thermal barrier coatings during thermal cycling, Acta Mater. 51 (2003) 2205-2217. 